Para una historia de la Historia argentina reciente en la escuela: inclusiones, dilemas, transformaciones y desafíos (1979-2018) María Paula GONZÁLEZ

Avances del Cesor, V. XVI, No 21, diciembre 2019, pp. 105-125.

ISSNe 2422-6580 / ISSN 1514-3899 - http://web2.rosario-conicet.gov.ar/ojs/index.php/AvancesCesor/index

\title{
Para una historia de la Historia argentina reciente en la escuela: inclusiones, dilemas, transformaciones y desafíos \\ (1979-2018)
}

\section{For a history of Recent Argentine history in school: inclusions, dilemmas, transformations and challenges (1979-2018)}

\author{
María Paula González \\ Universidad Nacional de General Sarmiento \\ Consejo Nacional de Investigaciones Científicas y Técnicas \\ mpgonzal@campus.ungs.edu.ar
}

(Argentina)

\section{Resumen}

La historia argentina reciente -en particular la concerniente a última dictadura- forma parte de la enseñanza de la historia del nivel secundario en Argentina. Así lo manifiestan diversas fuentes (legislación educativa, diseños curriculares, libros de textos escolares, materiales didácticos) y lo demuestran varias indagaciones sobre su tratamiento escolar. Ahora bien, ¿cómo y cuándo se produjo tal inclusión? ¿Qué cambios se produjeron en la década del noventa? ¿Qué transformaciones se dieron en los años dos mil? Este trabajo indicará una serie de elementos políticos, jurídicos, memoriales, historiográficos y pedagógicos así como sus mutaciones a lo largo de casi cuarenta años, elementos que -en conjunto y de manera conectada- permiten comprender los dilemas iniciales, interpretar las sucesivas transformaciones así como advertir los desafíos actuales de la historia argentina reciente en la escuela.

Palabras Clave: Historia reciente, dictadura, escuela. 


\begin{abstract}
The Recent Argentine history - and in particular, the one related to the last dictatorship - is a content in Argentina's secondary schools. This is stated by various sources (educational legislation, curricular designs, school textbooks, materials) and is shown by several inquiries about its school treatment. How and when was it included? Which changes occurred in the nineties? Which transformations occurred in the 2000s? This work will identify a series of political, juridical, memorial, historiographic and pedagogical elements as well as their mutations over almost forty years. These elements - put together and in a connected way allow to understand the initial dilemmas, as well as to make sense on succeeding transformations, in order to gaze on the current challenges of argentine's recent history teaching in school.
\end{abstract}

Keywords: recent history, dictatorship, school.

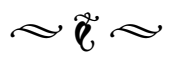

\section{Introducción}

En Argentina, la inclusión de la historia argentina reciente en la escuela secundaria -particularmente la última dictadura (1976-1983)ha quedado asociada a la Ley Federal de Educación sancionada en 1993. Sin embargo, ese contenido trasciende tal periodización y puede rastrearse su presencia curricular durante la propia etapa dictatorial. Al mismo tiempo, una mirada a los años ' 80 deja al descubierto importantes transformaciones en pos de la democratización educativa que, aunque no significaran alteraciones a los programas de estudio de historia, sí introdujeron al pasado reciente en otros espacios y dispositivos escolares. Asimismo, se pueden considerar múltiples inclusiones de esa temática en los contenidos a enseñar (y no, una inclusión en singular) toda vez que, en cada modificación del currículo, se introdujeron diversos modos de nombrar a la última dictadura.

Del mismo modo, varios estudios coinciden en señalar que la historia reciente en la escuela ha quedado anclada en la rutina de la condena y la memoria. Sin embargo, se debe señalar que muchas veces no consideran los sucesivos cambios memoriales, políticos y judiciales respecto de los crímenes de la última dictadura que condicionaron su tratamiento en la escuela y no tienen en cuenta las indagaciones que han puesto de manifiesto diferentes ensayos escolares y docentes que se han hecho cargo (no sin tensiones ni límites) de ese pasado.

Por lo dicho, este trabajo se propone exponer, precisamente, cómo fue incluida y cómo se fue transformando la historia argentina reciente en la escuela secundaria durante los últimos cuarenta años. La perspectiva asumida en este escrito es que sus características y alcances resultan comprensibles si se consideran -en conjunto y de manera conectada- una serie de elementos políticos, jurídicos, memoriales, historiográficos y pedagógicos así como sus mutaciones a lo largo del tiempo. Todo ello permite, además, percibir los dilemas iniciales, interpretar los sucesivos cambios así como advertir los desafíos actuales. 


\section{La historia reciente en los años de la dictadura}

Durante buena parte del siglo XX, la historia escolar quedó anclada al estudio del siglo XIX. Fue recién en 1979 que tal situación comenzó a cambiar, año en el que la propia dictadura incluyó el estudio de la historia más reciente en el nivel medio. ${ }^{1}$ En aquel año, el gobierno militar dispuso una modificación parcial de los contenidos de Historia del nivel medio. En particular, se reformularon los del ciclo básico de secundaria con dos innovaciones: por un lado, la introducción de una mirada en paralelo entre la historia argentina y mundial; por el otro, el abordaje de procesos de historia argentina desde 1930 hasta la actualidad (de aquel presente). Esto último resultó una novedad de gran importancia si se tiene en cuenta la tradición de tratar los lejanos tiempos de esa asignatura. ${ }^{2}$ De esa manera, en la última unidad del programa de 3er año elaborado por el Ministerio de Cultura y Educación (en adelante $\mathrm{MCyE}$ ) se incluyeron los siguientes contenidos

a. La Argentina a partir de 1930: los gobiernos desde 1930 hasta la revolución de 1943. Génesis y desarrollo del peronismo. La Revolución libertadora. Evolución posterior. La agresión y derrota de la subversión marxista. La Argentina en el mundo

b. La Italia fascista y la Alemania nazi. La era de Stalin. Estados Unidos y el "New

1. Isabelino Siede (2016) rastrea una paradoja similar para el tema de los Derechos Humanos y encuentra que quienes incluyen esta categoría en los programas de estudio son las dictaduras militares iniciadas en 1955 y 1976.

2. Los programas del ciclo superior de secundaria permanecieron sin modificaciones por lo cual quedó vigente el plan de 1956 que trataba la era colonial y el siglo XIX (Ministerio de Educación y Justicia, 1956)
Deal". Las relaciones internacionales. La Guerra Civil Española. La Segunda Guerra Mundial. Las Naciones Unidas. La "Guerra Fría”. La descolonización y la agresión mundial comunista. Las grandes potencias occidentales. Japón. El Concilio Vaticano II. Los grandes cambios científicos, técnicos y culturales contemporáneos. ( $\mathrm{MCyE}$, 1980$, p. 9$)^{3}$

Desde luego, tales contenidos reproducían la perspectiva política del gobierno dictatorial en torno a la historia argentina post-55 y formaron parte de la estrategia de autolegitimación (Born, 2010). La lectura de la "agresión marxista" que atentaba contra el "ser nacional" estuvo en la base del discurso militar que concebía a un enemigo inconmensurable al que solo se podía "derrotar" a través de una "guerra". Los subversivos eran considerados delincuentes "apátridas" que respondían a intereses conspirativos de un "terrorismo internacional" (Lvovich y Bisquert, 2008), idea que también se reflejaba en el diseño curricular cuando, en la subunidad dedicada a la historia mundial, se indicaba el estudio de "la agresión mundial comunista". De hecho, al proponer una mirada paralela entre la historia argentina y la historia mundial, se enfatizaba la idea de que la ofensiva subversiva que sufría Argentina era, en realidad, de alcance planetario.

Esas incorporaciones pueden ser apreciadas mejor si se tienen en cuenta los objetivos educativos generales de la Historia como asignatura escolar. En tal sentido, entre los propósitos de tal disciplina se señalaban cuestiones tales como "relacionar la historia argentina con la civilización occidental", "valorar la influencia, significación y transcendencia de la cultura cristiana en la conformación de los valores fun-

3. Las cursivas son mías. 
damentales de la civilización occidental específicamente en el proceso de integración de las culturas americanas con la tradición europea e hispánica y en su ulterior desarrollo hasta la realidad argentina contemporánea", "valorar la historia nacional y la obra de los hombres próceres como arquetipos en la orientación de las conductas personales y sociales", etc. (MCyE, 1980, pp. 4-5). Así, la historia escolar ancló en una perspectiva civilizatoria, occidental, blanca y cristiana como elementos propios de la identidad argentina que tenía por modelos a los próceres (la mayoría militares). En otras palabras, el relato escolar amarró en la "esencia" de la nacionalidad argentina, de la que no formaba parte "la delincuencia subversiva marxista apátrida" y de la cual la Iglesia y las Fuerzas Armadas siempre se habían adjudicado el papel de salvaguardas (Zanatta, 1996). Esta impronta curricular estuvo asociada, además, a otras decisiones referidas al tratamiento de la historia en el mundo escolar a través de nuevas efemérides, como las conmemoraciones de la Conquista del Desierto, la Generación del '80, la llegada del primer contingente de alemanes, entre otras (Rodríguez, 2009). Asimismo, los cambios en los contenidos oficiales fueron acompañados por la circulación de libros de texto escolares publicados en aquellos años que -de modo generalizado- reprodujeron los términos enunciados en el programa de Historia (Born, 2010; Zysman, 2015).

Todo esto, a su vez, se relacionaba con los objetivos generales de la educación que se enfocaban en la formación de hábitos y actitudes religioso-morales y el desarrollo de criterios y actitudes cívico-sociales aun cuando también fueran mencionadas finalidades tales como el cultivo del espíritu de investigación, la capacidad creadora y el pensamiento científico (MCyE, 1977a, p. 10). En este escenario, los docentes cumplían un rol prioritario en la "acción de transmisión generacional por la cual se efectiviza la continuidad de nuestra cultura tradicional y de la filosofía que la orienta", razón por la cual los educadores recibieron el calificativo de "custodios de nuestra soberanía ideológica” (MCyE, 1977b, p. 60). En términos todavía más amplios, puede señalarse que la implementación de esas directrices para la enseñanza de la historia estuvieron enmarcadas en una serie de políticas de perfil disciplinador y autoritario además de represivo y discriminador (Tedesco, Braslavsky y Carciofi, 1983; Pineau, 2014)

Visto en perspectiva, la reforma de 1979 implicó la introducción de la historia contemporánea y reciente pero eso no significó una actualización o renovación en los contenidos y objetivos si se compara con programas anteriores. Por el contrario, la propuesta no sólo privilegió la información política e institucional y la exclusión de contenidos vinculados a la organización social y cultural sino que, además, acentuó la exaltación nacional y el espíritu católico (Lanza, 1993; Kaufmann y Doval, 2006).

Ahora bien, terminada la dictadura ¿cómo fue leído y escrito el pasado reciente después de diciembre de 1983? ¿Cómo fue leído y escrito en clave escolar? Sobre esta cuestión, se avanzará en el siguiente apartado.

\section{Los dilemas de los años posdictatoriales: inercias y latencias}

La temprana labor de los organismos de Derechos Humanos durante la misma dictadura ${ }^{4}$

4.Hacia 1980 había informes que confirmaban las denuncias de los Organismos de Derechos Humanos, 
y, sobre todo, la investigación de la Comisión Nacional sobre la Desaparición de Personas (en adelante, CONADEP), ${ }^{5}$ la publicación de sus resultados en el informe Nunca Más así como el Juicio a las Juntas Militares ${ }^{6}$ permitieron escribir un relato diferente en torno al pasado reciente argentino. En efecto, esos hitos permitieron construir una narrativa renovada sobre lo acontecido entre 1976 y 1983 ya que contradijeron el discurso de la "guerra sucia contra la subversión" transmitida por la corporación militar. A través de una serie de pruebas $\mathrm{y}$ actos de justicia, se puso en evidencia a un Estado terrorista que llevó a cabo un plan sistemático de secuestro, tortura, asesinato además de cárcel y exilio para los disidentes. En otras palabras, el pasado dictatorial fue leído y escrito de otra manera: a través del "canon del Nunca Más". Con esta noción me refiero a la idea de la instauración del terrorismo de Estado por parte de las Fuerzas Armadas durante la última dictadura que localiza allí "el mal" al tiempo que introduce una visión retrospectiva expurgada y pacificada de la sociedad (Vezzetti, 2002 y Crenzel, 2008).

¿Cuáles fueron los límites de esa narrativa? El “canon del Nunca Más” clausuró un debate

por ejemplo, el Informe de la Comisión Interamericana de Derechos Humanos y las publicaciones del Centro de Estudios Legales y Sociales (CELS) que dejaban en evidencia el funcionamiento de un Estado terrorista.

5. Creada por Alfonsín en diciembre de 1983 para investigar las violaciones a los derechos humanos durante la última dictadura militar (1976-1983).

6. En abril de 1985, y por orden del presidente Alfonsín, se inició el juicio civil a las cúpulas militares por su responsabilidad en los crímenes y desapariciones durante la última dictadura. La Cámara Federal de la ciudad de Buenos Aires sentenció a prisión perpetua a los jefes del Ejército y la Armada miembros de la primera Junta militar, y a prisiones más cortas o absoluciones a militares de las otras Juntas. necesario acerca de los consensos, conformidades y complicidades en torno a la dictadura; inhibió la reflexión sobre la responsabilidad de las organizaciones armadas; obliteró la revisión de las actitudes de los partidos políticos, la connivencia de los grupos empresarios, la colaboración o el silencio de los medios de comunicación, la condescendencia de la cúpula eclesiástica; en síntesis, la responsabilidad de la sociedad civil frente al gobierno militar (lo que, por supuesto, no significa hablar de una sociedad como toda culpable). Es lo que señalara Hilda Sábato (2000) en relación con "el contexto mental y cultural en que los crímenes fueron posibles" haciendo hincapié no tanto en el aspecto jurídico sino en la dimensión social del clima de ideas predominante durante esos años de terror.Todas esas zonas opacas de la construcción de la memoria impidieron avanzar en explicaciones más complejas acerca de las condiciones que hicieron posible la instauración de la dictadura y se circunscribieron al recuerdo y al imperativo ético de la no repetición. La ausencia de examen crítico del pasado y de las responsabilidades colectivas fue consecuencia, también, del formato que adoptaron las luchas por la memoria en la transición democrática. En ese contexto, la figura del detenido-desaparecido y los supervivientes de los centros clandestinos de detención fueron sujetos despolitizados en los reclamos de los organismos de Derechos Humanos, en la estrategia jurídica de la fiscalía en el Juicio a las Juntas y en el propio informe de la CONADEP (Crenzel, 2008).

Pero más allá de los límites, por sus silencios y omisiones, el Nunca Más y el Juicio a las Juntas posibilitaron que se reconocieran públicamente los crímenes y desapariciones, se asumiera la envergadura de un Estado terrorista, se enjuiciara y condenara a los culpables a través de 
sus cúpulas. Los frenos a la profundización de la justicia -por la sanción de las leyes de Punto Final (1986) y Obediencia Debida (1987)- no pudieron borrar esos actos fundacionales de la memoria en Argentina. ${ }^{7}$

En ese contexto político y memorial de los años posdictatoriales, los contenidos de la historia escolar en secundaria no tuvieron modificaciones sustanciales a nivel oficial y masivo. Esa asignatura no fue objeto de renovación inmediata, a diferencia de otras como Educación Cívica. ${ }^{8}$ Por ello, los contenidos en esos primeros años de democracia fueron los mismos que los indicados en la guía programática de 1980, es decir, los que la propia dictadura había renovado para el ciclo básico de secundaria, mientras que para el ciclo superior siguió en vigencia el plan de $1956 .{ }^{9}$ En otras palabas, los programas vigentes en los primeros años de democracia reprodujeron los términos de "agresión y derrota de la subversión marxista", versión que se prolongó en en sucesivas reimpresiones de libros de textos escolares después del fin de la dictadura (Zysman, 2015; Born,

7. La ley de "Punto final" estableció una fecha tope para la presentación de denuncias de violaciones de derechos humanos acaecidos durante la dictadura militar limitando la apertura de causas judiciales. A contrapelo de la ley, se multiplicaron las presentaciones de denuncias y fueron procesados más de 300 oficiales. La ley de "obediencia debida" impedía juzgar a los cuadros militares intermedios y bajos al establecer que su actuación se enmarcaba en los principios y jerarquías militares de un acatamiento obligado de órdenes, por lo que sus actos no eran punibles.

8. En marzo de 1984 esa asignatura ya tenía un nuevo programa. Los contenidos de Educación Cívica según Resolución ministerial 536/84 reemplazaron la Formación Moral y Cívica estipulada en la dictadura por la Resolución 1614/80.

9. En los planes y programas publicados en 1984, en el apartado de la asignatura Historia, se indica que los contenidos responden a la Resolución ministerial 254/79.
2010). Así, en la enseñanza de la historia también puede verse que "los primeros tiempos de la llamada "transición a la democracia" constituyeron un momento mucho más abierto, incierto, ambiguo y lleno de continuidades y dilemas cuya resolución no era obvia ni evidente" (Feld y Franco, 2015, p. 11) y no fueron una etapa de transformación ni radical ni automática de valores y sentidos respecto al inmediato pasado dictatorial. Por el contrario, y como señalan las citadas autoras, hacia 1984, la "lucha antisubversiva" no parecía ser tan condenable y la noción de "guerra" no cambió de inmediato.

No obstante, no todo fue continuidad. Según Tiramonti (2006), el programa educativo del alfonsinismo tuvo dos propósitos principales. Por un lado, recuperar el perfil de país integrado, igualitario, inclusivo y educado así como extender los beneficios a aquellos sectores sociales desfavorecidos por los gobiernos dictatoriales. Por otro, modificar los patrones socializadores de las escuelas orientándolos hacia la conformación de una identidad ciudadana compatible con los valores del liberalismo político y de un orden democrático basado en la participación pluralista y las instituciones representativas. En conjunto, las líneas políticas procuraron: cambiar el currículo; transformar los valores y las prácticas institucionales a favor de una construcción democrática y participativa; eliminar las restricciones al ingreso en el nivel medio y superior; recuperar el debate público en materia educativa, entre otras cuestiones. La renovación de contenidos, sin embargo, no fue general sino restringida a un programa piloto para algunas escuelas secundarias. Además, si bien el debate fue intenso y extendido en torno al Congreso Pedagógico desarrollado durante el mandato de Raúl Alfonsín (19831989) éste no tuvo éxito en su intento de refundar el sistema educativo (aunque instaló la 
necesidad de una nueva ley educativa que se lograría años después y con otro gobierno). ${ }^{10}$

Visto en perspectiva, la etapa post 1983 fue un momento de cambios y continuidades. De continuidades en los planes de historia. De cambios en las múltiples resoluciones ministeriales que bregaban por la democratización de las prácticas escolares y por los intentos -aunque limitados- de transformación en el nivel secundario. ${ }^{11} \mathrm{Y}$ es que, a pesar que los contenidos oficiales e incluso muchos manuales escolares no se modificaron, aparecieron otras voces y nuevos enunciados al tiempo que se tomaron decisiones que buscaron instalar una nueva mirada sobre la historia argentina reciente en la escuela.

Ya el propio informe de la CONADEP en 1984 había apuntado en sus recomendaciones finales la necesidad de sancionar normas que tendieran a "establecer la enseñanza obligatoria de la defensa y difusión de los Derechos Humanos en los organismos docentes del Estado sean civiles, militares o de seguridad" (CONADEP, 1984, pp. 477-478). En

10. En la década del ' 80 y ' 90 hubo otras reformas de los contenidos de secundaria en diversas provincias que apuntaron a la integración de contenidos por áreas (Dussel, 1994)

11. En 1988 se aprobó la resolución 1624 que apuntaba a la transformación del Ciclo Básico de la Educación Media a través de la actualización científica y pedagógica de su diseño curricular que, sin embargo, se aplicó en una cantidad acotada de establecimientos secundarios. En aquella resolución, además de incluir el ya indicado afán democratizador, se sumaron menciones sobre la necesaria transformación de las instituciones educativas para favorecer la función activa del alumno en el proceso de aprendizaje y de los docentes como participantes creativos del diseño curricular. Tales menciones, por tanto, distaban de aquellos designios propios de la dictadura que buscaban formar al alumno obediente y contar con docentes como custodios de la soberanía ideológica. esa senda, en algunas jurisdicciones (como la provincia de Buenos Aires) se comenzaron a realizar conmemoraciones escolares referidas a la última dictadura. ${ }^{12}$ Asimismo, en otras asignaturas (como la nueva Educación Cívica) se comenzaron a estudiar los sucesivos golpes de Estado en Argentina incluido el último ( $\mathrm{Fi}-$ nocchio, 2007)

En resumen, los rasgos de la historia argentina reciente en la escuela media en los años posdictoriales evidencian transformaciones, inercias y latencias que también se dieron en otras dimensiones sociales, políticas y académicas. Por un lado, avances y retrocesos judiciales en la condena a los responsables militares de la dictadura. Por otro, avances en políticas de democratización del sistema educativo pero inercias en los programas de historia que no se modificaron y en los libros de textos escolares que continuaron editando la versión dictatorial de la dictadura. Finalmente, latencias del propio campo historiográfico que no había avanzado en el estudio de la última dictadura ( $\mathrm{y}$ lo hizo recién a mediados de los años '90). En la siguiente década, varios de estos elementos se transformaron tal como se verá en el próximo apartado.

12. En 1988, en la provincia de Buenos Aires se sancionó la ley 10671 que instituyó el día 16 de setiembre como "Día de la reafirmación de los derechos del estudiante secundario". En su articulado, la ley disponía la realización de: "clases alusivas a esta conmemoración, al tema Democracia y Derechos Humanos, brindando información sobre los sucesos acaecidos el 16 de septiembre de 1976, remarcando la importancia de los valores democráticos en contraposición a la arbitrariedad de los regímenes dictatoriales". Sobre esta cuestión, véase Raggio (2017a). 


\section{Los cambios en los años noventa}

En 1993 se sancionó la Ley Federal de Educación que reemplazó la decimonónica ley 1420 de 1884. Ese nuevo marco legislativo general, sin descartar el papel de la educación en la consolidación de la identidad nacional (propia de la ley del siglo XIX) propuso la formación de ciudadanos responsables, protagonistas críticos y transformadores de la sociedad para el fortalecimiento de la democracia $(\mathrm{MCyE}$, 1993). ${ }^{13}$

A partir de este marco legislativo, se avanzó en el diseño de los Contenidos Básicos Comunes (en adelante, $\mathrm{CBC}$ ) para todos los niveles educativos a nivel nacional, como la Educación General Básica (en adelante, EGB) y el nivel Polimodal. Allí, la historia argentina reciente fue incluida como parte del área de las Ciencias Sociales. En el caso del noveno año de la EGB3 se prescribieron los siguientes contenidos:

Inestabilidad política, golpes militares. La violencia política y los gobiernos autoritarios. La transformación económica. E1 endeudamiento externo. La guerra de las Malvinas y la crisis del autoritarismo. La reconstrucción de la democracia $(\mathrm{MCyE}$, 1995, p. 199)

Por su parte, en los CBC del Polimodal para Ciencias Sociales y, puntualmente, entre los contenidos conceptuales referidos a la sociedad y la política de "La Argentina Contemporánea” se señalaron:

Los proyectos políticos en disputa durante la primera mitad del siglo XIX. La formación

13. Véase particularmente Título II, Capítulo I, artículo 5, inciso 3 y artículo 6 de la Ley 24195 (MCyE, 1993). del Estado Nacional. Diferentes formas de relación entre el Estado y la sociedad desde 1880. Procesos históricos de configuración del Estado. Políticas públicas. Cambios en los regímenes políticos. Procesos democratizadores y procesos autoritarios. Rol de los actores políticos. Pensamiento político y social en la Argentina contemporánea: autores y corrientes significativas. La cultura política argentina: continuidades y transformaciones. Formas de ciudadanía política en la Argentina contemporánea. La experiencia política de los países del Mercosur. (MCyE, 1997, p. 11).

En paralelo a la puesta en marcha de los diseños curriculares derivados de la Ley Federal de Educación, comenzaron también a publicarse algunos trabajos que reflexionaban sobre los dilemas inherentes al tratamiento de la última dictadura en la escuela. En su mayoría, los autores coincidían en el planteo de interrogantes tales como ¿qué recordar?, ¿para qué?, ¿por qué y cómo hacerlo en la escuela?, ¿por qué y cómo hacerlo en enseñanza de la historia? ${ }^{14}$

Por un lado, algunos autores señalaban las dificultades derivadas de tratar un tema atravesado por la violencia y el dolor (Dussel, Finocchio y Gojman, 1997; Dussel, 2001). Frente a eso, la alternativa que planteaban era trabajar con marcos de referencia explicativos que permitieran referir a la historia política y social de nuestro país y discutir filosófica y políticamente cuestiones tales como la violencia y la construcción de la memoria. Por otro lado, otros

14. Desde luego, esas preguntas no fueron privativas de esos años. Cuando se puso en marcha el programa Educación y Memoria en el Ministerio de Educación de la Nación (ME), algunas preguntas se repetían entre quienes elaboraron materiales educativos. Véase al respecto Adamoli y otros (2015, p. 227 y ss.) 
trabajos referían a la escasa y dispar bibliografía sobre el pasado reciente, al tratamiento desparejo e insuficiente en los manuales escolares y a la falta de formación docente sobre esos temas (De Amézola, 1999; Raggio, 2002). Además, también varios escritos discutieron la idea tan común de "recordar para no repetir" y en su lugar propusieron pensar en términos análogos a los planteados por Todorov (2000) con la noción de "memoria ejemplar", esto es, "brindar a los alumnos elementos de análisis que les resulten útiles para la percepción de futuras realidades que se aprestan a vivir" (Guelerman, 2001, p. 39). Raggio (2002) también lo indicaba al afirmar que "recordar no garantiza no repetir, no obstante constituya su utopía. Recordar implica develar y asumir las condiciones que hicieron posible el pasado para reconocerlas en el presente" (p. 46).

En balance, todos los trabajos citados (y muchos otros) destacaban -de manera directa o indirecta- los principales riesgos del tratamiento de la historia argentina reciente en aquel contexto propio de los años'90 y mediados de los 2000. Esos riesgos eran la banalización, la cristalización de sentidos, la ritualización del pasado. $\mathrm{Al}$ respecto, y a modo de ejemplo, Federico Lorenz (2006) afirmaba que, desde los años' 80 hasta mediados de los 2000, la escuela había hecho hincapié en la memoria, la denuncia y la condena (por ejemplo, a través del uso del film La noche de los lápices) y que era necesario orientar su atención hacia la comprensión de ese pasado reponiendo su contexto histórico.

Al tiempo que varios autores indicaban los dilemas del tratamiento escolar de la historia reciente, una serie de indagaciones comenzaron a identificar las dificultades manifestadas por los propios docentes. Por ejemplo, De Amézola, Geoghegan y Carlos (2006) documentaron que los profesores señalaban que los problemas más acuciantes eran la falta de materiales y de referencias historiográficas, la nula formación docente recibida así como los conflictos en algunas instituciones escolares. En paralelo, otra exploración (González, 2014) exponía que los docentes adscribían a posiciones políticas diversas -desde la adhesión al golpe y la teoría de "la guerra sucia", pasando por la "teoría de los dos demonios" hasta la valoración de la militancia, etc.- pero que, en clave escolar, la traducción de la historia reciente se realizaba desde el canon del Nunca Más. Asimismo, esa investigación mostraba que muchos profesores- aun sin materiales, referencias y formación sistemática- desplegaban múltiples tácticas para hacerse cargo del pasado reciente en distintas "atmósferas de transmisión" institucionales (rechazo, omisión, rutina o aliento).

Ahora bien, ¿cómo explicar los dilemas planteados por los especialistas del campo historiográfico y educativo? ¿Cómo comprender los problemas que manifestaban los docentes? Para ello, resulta ineludible atender a una serie de condiciones más vastas.

En primer lugar, el tímido alcance de la historia argentina reciente incluida en los diseños curriculares. Como se citó, los contenidos conceptuales enunciados eran generales, amplios e imprecisos: para la EGB se hacía referencia a la "inestabilidad política", los "golpes militares" y "la violencia política y los gobiernos autoritarios" mientras que para el caso del nivel Polimodal se señalaban "procesos democratizadores y procesos autoritarios".

En segundo lugar, el dispar tratamiento de la última dictadura en los libros de texto escolares editados en los años '90 (De Amézola, 
1999 y 2006; Alonso, 2006; Reta y Pescader, 2002; Born, 2010). Al respecto, un estudio señalaba que esas publicaciones incluían "representaciones diferentes del pasado reciente, notables desde el espacio que se les destina en el conjunto del libro y, en relación con eso, desde la profundidad en el tratamiento de los temas" (Reta y Pescader, 2002, p.63).

En tercer lugar, la falta de materiales para la enseñanza alternativos a los libros de texto escolares. ${ }^{15}$ En efecto, por aquellos años, uno de los pocos recursos editados para el último ciclo de la EGB y el Polimodal era la selección de fuentes "La dictadura. Testimonios y documentos (1976-1983)" publicado por la Universidad de Buenos Aires (Caraballo, Charlier y Garulli, 1996) y "Haciendo memoria en el país del Nunca Más" por la editorial de esa misma universidad un año después (Dussel, Finocchio y Gojman, 1997). Este último material tuvo un mayor alcance en las escuelas porque fue enviado acompañando al informe de la CONADEP y, al incluir actividades para trabajar en las aulas, logró mayor difusión entre los docentes. ${ }^{16}$

En cuarto lugar, y de modo conexo con los puntos anteriores, la situación de la propia historiografía que acusó un largo y elocuente silencio hasta mediados de los '90 en torno al estudio de los años '70-'80 y, particularmente, sobre el período dictatorial (Pittaluga, 2007; Lvovich, 2007). Sobre esta falta de abordaje, se han señalado las limitaciones materiales e institucionales que afectaron a la investigación académica, la carencia más general de investigaciones sobre la historia argentina del último

15. Para una reseña más extensa y profunda de los materiales disponibles entre los años ' 80 y 2016, puede consultarse Ministerio de Educación y Deporte (2016).

16. Al respecto, véase Crenzel (2008 pp. 166 y ss.). medio siglo, la persistencia de actores comprometidos con la dictadura en las instituciones democráticas, la continuidad de la cultura del miedo, las trabas en el acceso a fuentes documentales, la imposibilidad de acceder a los archivos de las instituciones represivas e incluso el impacto de las políticas del olvido sobre los propios historiadores (Lvovich, 2007). Tal situación contrastaba con otros campos culturales y académicos que se abocaron a la reconstrucción el pasado cercano a través de diversas producciones (literatura, periodismo, cinematografía) y diferentes estudios (sociológicos, económicos, políticos), algunas de las cuales fueron usadas en muchas aulas. ${ }^{17}$

Pero además de tener en cuenta la situación curricular, material e historiográfica, para comprender los dilemas iniciales de la historia argentina reciente en la escuela también debemos atender a otra condición: el contexto político y memorial y los avatares de la justicia. ¿Qué sucedió con las luchas por la memoria, la verdad y la justicia en los años '90?

Como se dijo, después del informe de la CONADEP y de los Juicios a las Juntas, la posibilidad de profundizar el camino de la justicia fue frenada por las llamadas "leyes de impunidad" de 1986 y 1987. Luego de eso, el gobierno menemista tomó medidas aún más extremas: los indultos de 1989 y $1990 .{ }^{18}$ Así, a la etapa de juicio y castigo de la transición democrática le siguió un período donde se proclamó la necesidad del perdón y el olvido para lograr

17. Sobre las producciones del campo académico hasta 1999, véase De Amézola (1999). Sobre esa situación de la historiografía, Franco y Lvovich (2017).

18.Los indultos presidenciales de 1989 dejaron en libertad a más de 250 encarcelados y, en 1990, benefició a los comandantes de las Juntas Militares juzgados en 1985. 
la pacificación del país, es decir, la "teoría de la reconciliación nacional". Se instaba al "reconocimiento de errores propios y de aciertos del adversario" ${ }^{19}$ lo que implicaba, en última instancia, la igualación entre el terrorismo subversivo y el terrorismo de Estado de un modo mucho más potente que en el caso de la "teoría de los dos demonios", ${ }^{20}$ puesto que en la "reconciliación y pacificación" no había lugar para la justicia (como sí lo hubo en la narrativa de "los dos demonios") pero debía haberlo para el olvido y el perdón.

Visto en perspectiva, si la escuela quedó encerrada en la condena y la denuncia en torno a la última dictadura -entre los años ' 80 y ' 90 - se debió a la conjunción de elementos hasta aquí presentados: una inclusión curricular de corto alcance, la falta de materiales educativos, la escasez de referencias historiográficas y la clausura de los caminos de la justicia en Argentina. En los años siguientes, este panorama mutó profundamente como se verá a continuación.

\section{Las transformaciones de los años 2000}

Como se anticipó, las condiciones en las que se trabajó la historia argentina reciente en la escuela durante los años noventa se modificaron en los años 2000.

Para el caso de la legislación educativa y los diseños curriculares las transformaciones son por demás evidentes. En efecto, en 2004, el Ministerio de Educación Nacional (en adelan-

19. Palabras de los fundamentos del decreto de indultos. Véase al respecto Lvovich y Bisquert (2008, pp. 51-52).

20. Sobre esta teoría, véase Cerruti (2001). Para su discusión Franco (2015). te, $\mathrm{ME}$ ) inició un nuevo proceso de definición curricular identificando "Núcleos de Aprendizajes Prioritarios" (en adelante, NAP). Ese proceso tomó cuerpo en la publicación de la versión final de los NAP en 2006 para el ciclo básico y se completó en 2012 con los relativos al ciclo superior del nivel medio. Dentro de ellos, los referidos a la historia argentina reciente se incluyeron en noveno año del tercer ciclo de EGB/ Nivel Medio en el área de Ciencias Sociales, a través de los estos contenidos:

La comprensión de las múltiples causas que condujeron a una etapa de inestabilidad política en la Argentina en el período 19551976, identificando los diversos actores e intereses en juego (...) El conocimiento de las características del terrorismo de Estado implementado en la Argentina por la dictadura militar de 1976-1983, y de su relación con la Guerra Fría y la aplicación de un modelo económico y social neoliberal. (ME, 2006a, p. 25).

Del mismo modo, pero para el ciclo superior, en 2012, se aprobaron los siguientes:

La comprensión del golpe cívico-militar de 1976 y del Terrorismo de Estado como plan sistemático para destruir a las organizaciones populares y disciplinar a la sociedad, creando las condiciones de implementación del modelo económico neoliberal. La comprensión de la utilización de la Causa Malvinas por la dictadura de 1976-1983 para crear consenso social, y de las consecuencias de la guerra sobre el destino del régimen dictatorial y la democratización (ME, 2012, pp. 6-7).

Asimismo, la historia argentina reciente y la construcción de la memoria cobraron mayor 
relevancia y vigor en la Ley Nacional de Educación, sancionada en 2006. En este sentido, dicha ley -en su artículo 92- dispuso como contenidos curriculares comunes a todas las jurisdicciones:

El ejercicio y construcción de la memoria colectiva sobre los procesos históricos y políticos que quebraron el orden constitucional y terminaron instaurando el terrorismo de Estado, con el objeto de generar en los/ as alumnos/as reflexiones y sentimientos democráticos y de defensa del Estado de Derecho y la plena vigencia de los Derechos Humanos (...) (ME, 2006b, p. 19)

Mientras que la Ley Federal de 1993 resaltaba que la educación debía favorecer la "consolidación de la democracia", la Ley Nacional de 2006 no sólo respaldó esta función sino que añadió "el ejercicio y la construcción de la memoria colectiva" sobre el pasado reciente. Del mismo modo, puede verse también que los NAP del 2006 señalan que la enseñanza debe apuntar al "conocimiento de las características del terrorismo de Estado implementado en la Argentina por la dictadura militar de 19761983". En este sentido, la alusión al "terrorismo de Estado" resulta una definición más taxativa que "golpe militar" o "gobiernos autoritarios" de los CBC de 1995. Más aún puede advertirse (dentro de este mismo período) cómo se pasa de nombrar la "dictadura militar" en 2006 a indicar el "golpe cívico-militar" en 2012. ${ }^{21}$

Las luchas por la memoria explican, en gran medida, que esta mención se encuentre en el cuerpo de la nueva ley, luchas que, de modo notorio desde 2003 formaron parte de las "políticas de memoria por parte del Estado" (Lvovich

21. Para una discusión de esta categoría, véase Franco (2016). y Bisquert, 2008). Pero, además, desde 2002 se inició un camino diferente para la justicia: se declaró la inconstitucionalidad y nulidad de las leyes de impunidad, se retomaron las causas penales no solo a los militares sino también a civiles responsables de la dictadura. Además, el propio Estado reconoció su responsabilidad en la represión ilegal a través de reparaciones económicas, el resguardo de archivos y la construcción de espacios de memoria. ${ }^{22}$

Por su parte, la historiografía dedicada a los años '70 y' 80 también produjo un salto, tanto que pasó de ser considerada un "campo en construcción" (Franco y Levín, 2007) a un campo"en expansión" (Franco y Lvovich, 2017). Así lo demuestra la gran cantidad de indagaciones que han avanzado sobre las zonas grises y desatendidas de esos años: el consenso, la resignación, la complicidad y la conformidad de la sociedad civil frente a la dictadura; el accionar y la responsabilidad de las organizaciones armadas; las actitudes de los partidos políticos; la complicidad empresarial y eclesial; etc. a través de la ampliación de las escalas geográficas y temporales, los actores sometidos al análisis y los marcos teóricos y metodológicos adoptados (Bohoslavsky, Franco, Iglesias y Lvovich, 2010).

La situación de los materiales disponibles para la enseñanza de la historia argentina reciente también se modificó. En este caso, no solo los libros escolares ampliaron, modificaron y profundizaron su tratamiento en diálogo con las políticas de memoria (Acosta, 2015). Conjuntamente, se produjeron muchos otros recursos -textuales, audiovisuales y multimediales- es-

22. Sobre el reconocimiento discursivo: Kirchner en la ESMA: "En nombre del Estado, vengo a pedir perdón" (25 de marzo de 2004). Clarín. Sobre el reconocimiento del Estado y las políticas concretas, CELS (2004). 
pecialmente orientados a los profesores y las instituciones escolares para trabajar con los jóvenes con el fin de "pensar, aprender, debatir, enseñar y transitar juntos el camino de apropiarnos de la historia en tiempo presente para imaginar otros futuros posibles" (ME, 2010, p. 13). ${ }^{23}$

Pero, además de las modificaciones curriculares, los avances historiográficos, la creciente producción de materiales escolares, cabe preguntarse ¿qué pasó en las escuelas? ¿qué sucedió en las aulas de historia? Estas preguntas pueden ser contestadas desde estudios cuantitativos y cualitativos.

Desde el punto de vista cuantitativo, resulta interesante la indagación realizada por la $\mathrm{Fa}^{-}$ cultad de Ciencias Sociales de la Universidad de Buenos Aires junto al área de "Educación y Memoria" del Ministerio de Educación de la Nación durante el año 2015. ${ }^{24}$ Las conclusiones a las que arribó el estudio resultaron reveladoras: la escuela apareció con un rol central en la transmisión del pasado reciente. Mayoritariamente $(68,2 \%)$, los estudiantes respondieron que fue en ella donde escucharon hablar de la última dictadura con más frecuencia, en comparación con lo recepcionado desde los medios masivos de comunicación como la televisión $(13,4 \%)$ o de ámbitos privados como el hogar (11,9\%) (Levy y Gerzovich, 2016). Asimismo, el relevamiento mostraba que el

23. Cabe señalar las diversas producciones multimediales del programa Conectar igualdad, los materiales audiovisuales producidos por el canal Encuentro y los materiales del Programa Educación y Memoria publicados entre 2005 y 2015. Sobre este último véase Adamoli, Farias y Flachsland (2015).

24. En esa ocasión, se tomaron encuestas a 2500 estudiantes en 37 escuelas públicas de todo el país.
96,3\% de los estudiantes identificaron en general como responsables de la dictadura a las Fuerzas Armadas mientras que las opciones por otras categorías que hablaban de responsabilidades civil, corporativa y empresaria (iglesia, medios, empresarios, poder financiero e inclusive potencias extranjeras) sumaron solo el 4,4\%. En síntesis, la escuela aparece como lugar de memoria mientras que otros aspectos relacionados con la responsabilidad social más general aparecen con mucha menos fuerza siguiendo el derrotero académico que investigó estos temas más tardíamente. ${ }^{25}$ No obstante, también el informe destaca que las categorías asociadas a la "teoría de los dos demonios" -tales como "guerrilleros" y "subversivos"- solamente fueron mencionados por cinco jóvenes de mil ochocientos once. Nuevamente, entonces, el contexto memorial y los aportes académicos hacen comprensible lo que sucede en las escuelas.

Desde el punto de vista cualitativo, contamos hoy con una serie de exploraciones que abordan la enseñanza de la historia reciente en las aulas y que muestran, a partir de diversos casos, cómo se ha avanzado en el tratamiento de la dictadura (Higuera Rubio, 2010; Caldo y Scalona, 2011, Billán, 2015; Pappier, 2017; Legarralde, 2018). Estas investigaciones, lejos de mostrar a una escuela solo anclada en la denuncia y la condena, ponen en evidencia diversas prácticas de enseñanza que -no exentas de ciertas limitaciones y tensiones- son resultado de diversos modos de apropiarse del pasado reciente que proyectan nuevas formas de enseñar

25.. Tal situación ha sido documentada por Franco y Lvovich (2017). Como ejemplos de este tipo indagaciones centradas en responsabilidades civiles durante la última dictadura, véanse las realizadas por Bohoslavsky (2015) y Verbitsky y Bohoslavsky (2013). 
de los docentes y de hacer historia por parte de los jóvenes. ${ }^{26}$

En balance, los años 2000 (hasta fines del 2015) dejan a la vista una serie de transformaciones importantes para la enseñanza de la historia argentina en la escuela media. Por un lado, renovadas definiciones curriculares que profundizan los alcances de esta porción de la historia con clara intención política y memorial de condena al terrorismo de Estado. Por otro, la construcción y consolidación de un campo historiográfico que aporta saberes actualizados a los diseños, a los libros de texto escolares y a otros materiales así como a la formación docente. Conectado con lo anterior, una gran oferta de recursos educativos en diversos lenguajes y soportes acompañados por dispositivos de actualización docente. Por último, el avance de la justicia en la condena de los responsables (militares y civiles) de la última dictadura.

\section{Los desafíos en la actualidad}

La asunción de un nuevo gobierno en diciembre de 2015 ha supuesto un quiebre en relación con algunas de las condiciones analizadas en los apartados anteriores, en particular políticas y jurídicas. Si bien no contamos con la distancia suficiente para dilucidar sus alcances sobre algunos ámbitos (como las prácticas escolares), lo cierto es que desde la llegada de la alianza

26. A los trabajos que analizan la enseñanza en las aulas se deberían sumar aquellos que dan cuenta de las experiencias de trabajo extra áulicos (pero promovidos desde las escuelas) como el Programa "Jóvenes y Memoria" de la Comisión Provincial por la Memoria en la provincia de Buenos Aires. Al respecto, remitimos a Raggio (2017b).

118
Cambiemos al poder (e incluso algunos meses antes) se han producido varias mudanzas de discursos y prácticas en relación con el pasado reciente.

En referencia a los discursos, en diferentes foros y a través de la prensa escrita, se alzaron voces (políticas, académicas y periodísticas) que "relativizaron la magnitud y cualidad de los crímenes y la represión estatal durante los años setenta en la Argentina y cuestionaron los juicios penales en curso contra perpetradores de violaciones a los derechos humanos". ${ }^{27}$ Esas declaraciones implicaron diversas formas de descalificación o negación del conocimiento acumulado en torno al carácter sistemático y clandestino de los crímenes cometidos por la última dictadura militar y, además, facilitaron la aparición de discursos que incluso reivindican el accionar de las fuerzas armadas durante 1976 y $1983 . .^{28}$

Respecto a los cambios en las políticas, son evidentes sobre todo en aquellas vinculadas con los Derechos Humanos. ${ }^{29}$ En efecto, no solo se puso en cuestión la política de derechos humanos de décadas anteriores sino que se co-

27. Manifiesto "La democracia se construye con verdad y con justicia”. Recuperado de https://

historiarecienteargentina.wordpress.com Véase también, Preocupados por el proceso de justicia (22 de septiembre de 2015). Página 12. Sobre este cambio de época, véase además: Lorenz, F. (marzo de 2017). ¿Por qué vuelven los 70? Le Monde Diplomatique213. Recuperado de https:// www.eldiplo.org/213-derechos-humanos-cuestion-deestado/por-que-vuelven-los-70/

28.Véase, por ejemplo, las declaraciones de Gómez Centurión (por entonces titular de la Aduana) No comparto que hubo un plan genocida ( 29 de enero de 2017). Clarin.

29. Pablo Avelluto (ministro de Cultura de la Nación): Hoy tenemos también otra agenda, que tiene que ver con los Derechos Humanos de los vivos (24 de marzo de 2017). La Nación. 
menzaron a desarticular diversas áreas estatales que investigaban responsabilidades en los crímenes dictatoriales, aportaban pruebas a los juicios y/o asistían a las víctimas. ${ }^{30}$ En ese mar$\mathrm{co}$, si bien algunas causas judiciales en torno a crímenes de la dictadura siguen en pie y se han sumado condenas, han cambiado las condiciones por lo que la situación se ha vuelto contradictoria (CELS, 2017). En esta misma senda, y con impacto directo en el mundo escolar, se debilitaron o desfinanciaron programas y redes que habían sido claves en la realización de actualizaciones para docentes y en la producción de materiales educativos destinados a la difusión, reflexión y tratamiento escolar del terrorismo de Estado en las aulas. ${ }^{31}$

Ahora bien, aun cuando se vienen transformando los discursos y las políticas del actual gobierno, lo cierto es que la legislación educativa nacional y la normativa curricular no han sido modificadas todavía. Es decir, se registra un nuevo desacople (tal como se señaló para los años posdictatoriales) pero esta vez inverso: la escuela sigue bajo el mandato de trabajar en el "ejercicio y construcción de la memoria colectiva sobre los procesos históricos y políticos que quebraron el orden constitucional y terminaron instaurando el terrorismo de Estado" mientras que socialmente se escuchan $(\mathrm{y}$

30. Por ejemplo, el Grupo Especial de Relevamiento Documental, los Equipos de Relevamiento y Análisis de los Archivos de las Fuerzas Armadas, el Programa Verdad y Justicia, el Centro de Asistencia a Víctimas de Violaciones de Derechos Humanos Dr. Fernando Ulloa, la Subgerencia de Promoción de los Derechos Humanos del Banco Central, etc. Véase el Manifiesto Frente a la banalización del terrorismo de Estado y los derechos humanos, Recuperado de https://historiarecienteargentina. wordpress.com

31. Por ejemplo, el Programa Educación y Memoria del ME, la Red Nacional de Educación y Memoria y los diversos programas provinciales asociados. se habilitan) voces que ponen en cuestión esos términos e incluso vuelven a hablar de "guerra" para referirse a la última dictadura. ${ }^{32}$

No obstante, que los contenidos curriculares continúen inalterados no nos exime de pensar los desafíos que se presentan en este nuevo contexto político y memorial. Pareciera que en la escuela, pasados ya más de cuarenta años del golpe, vuelve a presentarse como urgencia (y no como algo ya superado) el deber de memoria, el deber de condena al terrorismo de Estado. Desde luego, esto no depende sólo de la escuela sino, sobre todo, de la fortaleza de un consenso social. Lo que la escuela puede aportar es que ese consenso se renueve en las jóvenes generaciones. Probablemente, los profesores tengan que seguir enseñando que no es lo mismo hablar de "guerra sucia" que de terrorismo de Estado. Quizás las escuelas deban hacer el doble esfuerzo de recordar y entender, de condenar e historizar.

\section{Conclusiones}

El recorrido propuesto en este trabajo ha puesto en evidencia, por un lado, cómo los campos político, jurídico, memorial y académico condicionan al campo escolar y, por otro, que la escuela no muestra correspondencias directas y mecánicas sino que alberga grados variables de autonomía.

Sobre la primera cuestión, se ha mostrado que el ingreso de la historia reciente en la enseñanza de la historia se produjo durante la última

32. Ese fue el término utilizado por el presidente Mauricio Macri en una entrevista donde además agregó "no tengo idea si hubo 30 mil desaparecidos". Recuperado de https://www.infobae.com/.../22-definiciones-demacri-en-su-entrevista-en-buzzfeed/Infobae, 10-8-2016 
dictadura y reproducía la perspectiva política de ese régimen al considerar la "agresión y derrota de la subversión marxista”. Del mismo modo, se ha indicado que en los primeros años de la posdictadura no se produjeron cambios curriculares pero sí se ensayaron modificaciones que bregaban por la democratización del sistema educativo. Luego, revisitados los años '90, se ha subrayado la importancia de la inclusión de la historia reciente asociada al fortalecimiento de la democracia. Al mismo tiempo, se han señalado los límites de tal inclusión al constatar el corto alcance de los enunciados, las pocas referencias historiográficas disponibles y la escasez de materiales didácticos alternativos. Seguidamente, analizados los años 2000, se ha puesto de manifiesto cómo se modificaron los diseños curriculares y se incluyeron enunciados tales como "terrorismo de Estado" y "dictadura cívico -militar" no solo con el afán de afianzar la democracia sino también para construir memoria. Finalmente, al observar los tiempos actuales, fue posible afirmar que aunque no se han modificado los contenidos escolares, los discursos políticos en torno a la dictadura sí han variado profundamente.

Sobre la segunda cuestión, también se ha considerado que la escuela alberga en ocasiones cierta autonomía que la desacopla de los tiempos políticos, historiográficos y memoriales. En ese sentido, en los años '80 las escuelas bregaron por la democratización de sus prácticas e incluyeron contenidos y conmemoraciones referidas a la última dictadura en otros espacios y con otras estrategias en contraste con la inmutabilidad de los programas de historia. Al mismo tiempo, se ha sostenido que inclusive durante los años '90 -en un contexto político, judicial y memorial más propenso al olvido- muchos docentes asumieron el desafío de enseñar el pasado reciente aun careciendo de referencias historiográficas y materiales didácticos. Finalmente, se ha mostrado cómo en los años 2000 las condiciones historiográficas, pedagógicas, políticas y memoriales para el tratamiento de la historia reciente se transformaron. Estos cambios tuvieron impacto directo en las escuelas que fueron ensayando diversos modos de transmitir pero también de habilitar la construcción de saberes y memorias en los jóvenes.

En conjunto, el trabajo ha pretendido demostrar la complejidad del mundo educativo y de la enseñanza de la historia y subrayar la alta politicidad de la historia reciente en la escuela así como el carácter intrínsecamente político del acto educativo.
Recibido: 12-11-2018

Aceptado: 01-03-2019

Publicado: 04-12 -2019 


\section{Referencias Bibliográficas}

Acosta, J. (2015). La historia reciente en la escuela. Análisis de los manuales del nivel medio luego de la sanción de la Ley Nacional de Educación en 2006. Clio E̊ Asociados, 20-21, 149-161.

Adamoli, M., Flachsland, C. y Farias, M. (2015). Educación y memoria. La historia de una política pública. Historia De La Educación. Anuario, 16(2), 225-241. Recuperado de http:/ppct.caicyt.gov.ar/index.php/ anuario/article/view/8386

Alonso, F. (2006). La dictadura militar argentina (1976-1983) en los textos de Ciencias Sociales e Historia para el tercer ciclo de la Educación General Básica. En C. Kaufmann (Dir.), Dictadura y educación. Los textos escolares en la historia argentina reciente (pp. 228-294). Buenos Aires: Miño y Dávila.

Billán, Y. (2105). Enseñar historia reciente en el ex partido de General Sarmiento. Un estudio de caso (Tesis de Maestría inédita). Maestría en Historia Contemporánea. Universidad Nacional de General Sarmiento, Los Polvorines, Provincia de Buenos Aires, Argentina.

Bohoslavsky, E., Franco, M., Iglesias, M. y Lvovich, D. (Comps.). (2010). Problemas de historia reciente del Cono Sur. Buenos Aires: Prometeo-UNGS (dos tomos).

Bohoslavsky, J. P. (Ed.) (2015) ¿Usted también, doctor?: Complicidad de jueces, fiscales y abogados durante la dictadura. Buenos Aires: Siglo Veintiuno Editores.

Born, D. (2010). Las representaciones de la última dictadura militar. Los textos escolares de bistoria en el nivel secundario de la Ciudad de Buenos Aires 1976-2009 (Tesis de maestría inédita). Maestría en Ciencias Sociales. FLACSO. Buenos Aires, Argentina

Caldo, P. y Scalona, E. (2011). De las prescripciones a las prácticas de la enseñanza del tema "última dictadura militar" en las escuelas secundarias. Análisis de casos para pensar la reforma curricular actual. Clío Ė asociados. La historia enseñada, (15), 233-255. Recuperado de https://bibliotecavirtual.unl.edu.ar/ publicaciones/index.php/ClioyAsociados/article/view/1703

Caraballo, L.,Charlier, N. y Garulli, L. (1996). La dictadura. Testimonios y documentos. Buenos Aires: Oficina de Publicaciones del CBC - UBA.

Centro de Estudios Legales y Sociales (2017). Derechos humanos en la Argentina. Informe 2017. Buenos Aires: Siglo XXI Editores Argentina.

Centro de Estudios Legales y Sociales (2004). Derechos humanos en la Argentina. Informe 2017. Buenos Aires: Siglo XXI Editores Argentina

Comisión Nacional sobre la Desaparición de Personas (1984). Nunca más. Informe de la Comisión Nacional sobre la Desaparición de Personas. Buenos Aires: Eudeba.

Crenzel, E. (2008). La historia política del Nunca más. La memoria de las desapariciones en la Argentina. Buenos Aires: Siglo XXI. 
Cerruti, G. (2001). La historia de la memoria. Entre la fetichización y el duelo. Puentes, 1(3), 14-25.

De Amézola, G. (1999). Problemas y dilemas de la enseñanza de la historia reciente. Entrepasados, Revista de Historia, 17, 137-162.

De Amézola, G. (2006). Cambiar la historia. Manuales escolares, curriculum y enseñanza de la historia reciente desde la "transformación educativa". En C. Kaufmann (Dir.), Dictadura y Educación. Los textos escolares en la historia argentina reciente (pp. 227-270). Buenos Aires: Miño y Dávila.

De Amézola, G., Carlos, M. y Geoghegan, E. (2006). La dictadura en la escuela. La enseñanza de la historia reciente en las escuelas de la Provincia de Buenos Aires. Recuperado de: http://www.riehr.com.ar/archivos/ Investigacion/La\%20dictadura\%20en\%201a\%20escuala,\%20de\%20Amezola\%20et\%20al.pdf

Dussel, I. (1994). El curriculum de la escuela media argentina: tendencias y perspectivas para la integración en el Mercosur en los diseños curriculares provinciales. Buenos Aires: FLACSO.

Dussel, I. (2001). La transmisión de la historia reciente. En S. Guelerman (Comp.), Memorias en presente. Identidad y transmisión en la Argentina posgenocidio (pp. 65-97). Buenos Aires: Norma.

Dussel, I, Finocchio, S. y Gojman, S. (1997). Haciendo memoria en el país de Nunca Más. Buenos Aires: Eudeba.

Feld, C. y Franco, M. (2015). Introducción. En C. Feldy M. Franco (Dir.), Democracia, hora cero. Actores, politicas y debates en los inicios de la posdictadura (pp. 9-21). Buenos Aires: Fondo de Cultura Económica.

Finocchio, S. (2007). Entradas educativas en los lugares de la memoria. En M. Franco y F. Levín (Comps.), Historia reciente. Perspectivas y desafios para un campo en construcción (pp. 253-277). Buenos Aires: Paidós.

Franco, M. (2016). La noción de "dictadura cívico-militar". En P. Flier (Coord.). (2016). Jornadas de Trabajo sobre Historia Reciente (La Plata, 2014). Actas (pp. 69-90). Ensenada: Universidad Nacional de La Plata. Facultad de Humanidades y Ciencias de la Educación. Recuperado de: http://www.memoria. fahce.unlp.edu.ar/libros/pm.463/pm.463.pdf

Franco, M. (2015). La "teoría de los dos demonios" en la primera etapa de la posdictadura. En C. Feld y M. Franco (Dirs.), Democracia, hora cero. Actores, politicas y debates en los inicios de la posdictadura (pp. 23-80). Buenos Aires: Fondo de Cultura Económica.

Franco, M.y Levín, F. (2007). El pasado reciente en clave historiográfica. En M. Franco y F. Levín (Comps.), Historia reciente. Perspectivas y desafios para un campo en construcción (pp. 31-65). Buenos Aires: Paidós.

Franco, M. y Lvovich, D. (2017). Historia Reciente: apuntes sobre un campo de investigación en expansión. Boletin Del Instituto De Historia Argentina y Americana "Dr. Emilio Ravignani", (47), 190-217. Recuperado de http://ravignani.institutos.filo.uba.ar/publicacion/n\%C2\%BA-47-julio-diciembre-2017 
González, M (2014). La bistoria argentina reciente en la escuela. Saberes y prácticas docentes en torno a la última dictadura. Los Polvorines: Publicaciones UNGS.

Guelerman, S. (2001). Escuela, juventud y genocidio. Una interpelación posible. En S. Guelerman (Comp.), Memorias en presente. Identidad y transmisión en la Argentina posgenocidio (pp. 35-64). Buenos Aires: Norma.

Higuera Rubio, D. (2010). La escuela ante la transmisión del pasado reciente argentino: sentidos comunes, dilemas de la representación y los desafíos del presente. Buenos Aires: Libros libres, FLACSO-Argentina. Recuperado de http://libroslibres.flacso.org.ar/sites/default/files/higuera1.pdf

Kaufmann, C. y Doval, D. (2006). La enseñanza encubierta de la religión: la 'formación moral y cívica'. En C. Kaufmann (Dir.), Dictadura y educación. Los textos escolares en la historia argentina reciente (pp. 203223). Buenos Aires: Miño y Dávila Editores.

Lanza, H. (1993). La propuesta oficial y la propuesta editorial para la enseñanza de la historia en la escuela media. En H. Lanza y S. Finocchio. Curriculum presente, ciencia ausente. La enseñanza de la bistoria en la Argentina de hoy (pp. 17-95). Buenos Aires: FLACSO/ CIID- Miño y Dávila Editores.

Legarralde, M. (2018). Combates por la memoria en la escuela. La transmisión de la última dictadura militar en las escuelas secundarias de la provincia de Buenos Aires (2008-2013) (Tesis doctoral inédita). Doctorado en Educación. Universidad Nacional de La Plata, La Plata, Argentina. Recuperado de http://sedici.unlp. edu.ar/handle/10915/67111

Levy, G. y Gerzovich, D. (2016). Proyecto Escuela y Memoria. Evaluación de políticas públicas de memoria. En Ciencias Sociales, (90), 126-137. Recuperado de http://www.sociales.uba.ar/wp-content/blogs.dir/219/ files/2016/03/24.-INFORME_LEVY_GERZOVICH_90.pdf

Lorenz, F. (2006). El pasado reciente en la Argentina: las difíciles relaciones entre transmisión, educación y memoria. En M. Carretero, A. Rosa y M. González.(Comps.), Enseñanza de la historia y memoria colectiva (pp. 277-295). Buenos Aires: Paidós.

Lvovich, D. (2007). Historia reciente de pasados traumáticos. De los fascismos y colaboracionismos europeos a la historia de la última dictadura argentina. En M. Franco y F. Levín, (Comps.), Historia reciente. Perspectivas y desafíos para un campo en construcción (pp. 97-124). Buenos Aires: Paidós.

Lvovich, D. y Bisquert, J. (2008). La cambiante memoria de la dictadura. Discursos públicos, movimientos sociales y legitimidad democrática. Los Polvorines: UNGS- Biblioteca Nacional.

Ministerio de Cultura y Educación (1977a). Resolución Ministerial 284/77. Objetivos pedagógicos del nivel primario y del nivel medio. Buenos Aires: Publicaciones del Ministerio.

Ministerio de Cultura y Educación (1977b). Subversión en el ámbito educativo. Conozcamos a nuestro enemigo. Buenos Aires: Publicaciones del Ministerio 
Ministerio de Cultura y Educación (1980). Resolución Ministerial 1709/80. Plan de estudios de Historia. Buenos Aires: Publicaciones del Ministerio.

Ministerio de Cultura y Justicia (1988). Resolución Ministerial 1624.Programa de Transformación de la Educación Media. Buenos Aires: Publicaciones del Ministerio.

Ministerio de Cultura y Educación (1993). Ley Federal de Educación 24195. Buenos Aires: Publicaciones del Consejo Federal de Educación.

Ministerio de Cultura y Educación (1995). Contenidos Básicos Comunes de Ciencias Sociales para la Educación General Básica (Ciencias Sociales Tercer ciclo). Buenos Aires: Publicaciones del Consejo Federal de Educación.

Ministerio de Cultura y Educación (1997). Contenidos Básicos Comunes de Ciencias Sociales para Polimodal. Buenos Aires: Publicaciones del Consejo Federal de Educación.

Ministerio de Educación (2006a). NAP Núcleos de Aprendizajes Prioritarios. EGB/Nivel medio. Buenos Aires: Publicaciones del Consejo Federal de Educación.

Ministerio de Educación (2006b). Ley Nacional de Educación 26206. Buenos Aires: Publicaciones del Consejo Federal de Educación.

Ministerio de Educación (2010). Pensar la dictadura: terrorismo de Estado en Argentina. Preguntas, respuestas y propuestas para su enseñanza. Buenos Aires: Programa Educación y Memoria.

Ministerio de Educación (2012). Núcleos de Aprendizajes Prioritarios. Ciencias Sociales, Ciclo orientado. Buenos Aires: Publicaciones del Consejo Federal de Educación.

Ministerio de Educación y Deportes de la Nación. Instituto Nacional de Formación Docente (2016). Con la mirada puesta en la escuela. Algunos materiales que abordaron la dictadura, el terrorismo de Estado y los Derechos Humanos desde la década del 80 al presente. Buenos Aires: Publicaciones del Ministerio.

Ministerio de Educación y Justicia (1956). Planes y Programas de Estudio. Buenos Aires: Publicación del Ministerio.

Pappier, V. (2017). La historia reciente en las aulas de nivel secundario: prácticas escolares en torno a la última dictadura argentina (Tesis de Maestría). Maestría en Historia y Memoria. Universidad Nacional de La Plata, La Plata, Argentina. Recuperado de http://sedici.unlp.edu.ar/handle/10915/61051

Pineau, P. (2014) Reprimir y discriminar. La educación en la última dictadura cívico-militar en Argentina (1976-1983). Educar em Revista, (51), 103-122.

Pittaluga, R. (2007). Miradas sobre el pasado reciente argentino. En M. Franco y F. Levín (Comps.), Historia reciente. Perspectivas y desafios para un campo en construcción (pp. 125-152). Buenos Aires: Paidós.

Raggio, S. (2017a). Memorias de la Noche de los Lápices. Tensiones, variaciones y conflictos en los modos de narrar el pasado reciente. La Plata: Universidad nacional de La Plata; Posadas: Universidad Nacional de Misio- 
nes; Los Polvorines: Universidad Nacional de General Sarmiento. Recuperado de http://libros.fahce. unlp.edu.ar/index.php/libros/catalog/book/98

Raggio, S. (2017b). Transmisión de la memoria: la experiencia en el encuentro con Otros. El largo proceso de institucionalización de la memoria en la escuela. Aletheia, 7(14). Recuperado de http://sedici.unlp. edu.ar/handle/10915/62088

Raggio, S.(2002). Cuando la escuela da la palabra. El rol de la educación formal en la transmisión del pasado. Revista Puentes, 7, 41-46.

Reta, M. y Pescader, C. (2002). Representaciones del pasado reciente. Análisis de los textos escolares de nivel medio. Clio y Asociados. La Historia Enseñada, (6), 50-70.

Rodríguez, L.(2009) La Historia que debía enseñarse durante la última dictadura militar en Argentina (1976- 1983).Antiteses, 2(3), 227-256.

Sábato, H. (2000) La cuestión de la culpa. Revista Puentes, 1(1), 14-17.

Siede, I. (2016) Peripecias de los Derechos Humanos. En el currículo escolar de Argentina. Buenos Aires: Eudeba.

Tedesco, J.; Braslavsky, C. y Carciofi, R. (1983). El proyecto educativo autoritario. Argentina 1976-1982. Buenos Aires: FLACSO.

Tiramonti, G. (2006). Las transformaciones de la política educativa nacional en los años de la democracia. Archivos De Ciencias De La Educación, 1(1). Recuperado de https://www.archivosdeciencias.fahce.unlp. edu.arl

Todorov, T. (2000). Los abusos de la memoria. Barcelona: Paidós.

Verbitsky, H. y Bohoslavsky, J. (Eds.). (2013). Cuentas pendientes. Los cómplices económicos de la dictadura. Buenos Aires: Siglo Veintiuno editores.

Vezzetti, H. (2002). Pasado y presente. Guerra, dictadura y sociedad en la Argentina. Buenos Aires: Siglo XXI.

Zanatta, L. (1996). Del Estado liberal a la Nación católica. Bernal: Universidad Nacional de Quilmes.

Zysman, N. (2015). De la "subversión marxista" al "terrorismo de Estado". Representaciones de la última dictadura militar en las narrativas históricas de la escuela media argentina (1983-2009). Villa María: EDUVIM. 